\title{
Effect of Aerobic Training on Body Composition among Sedentary Women of Manipur
}

\author{
Loitongbam Baby Sujata Devi", Takhellambam Inaobi Singh \\ Department of Physical Education and Sports Science, Manipur University, Canchipur, India
}

Received March 16, 2021; Revised May 20, 2021; Accepted June 6, 2021

\section{Cite This Paper in the following Citation Styles}

(a): [1] Loitongbam Baby Sujata Devi, Takhellambam Inaobi Singh, "Effect of Aerobic Training on Body Composition among Sedentary Women of Manipur, "International Journal of Human Movement and Sports Sciences, Vol. 9, No. 4, pp. 712 - 716, 2021. DOI: 10.13189/saj.2021.090415.

(b): Loitongbam Baby Sujata Devi, Takhellambam Inaobi Singh (2021). Effect of Aerobic Training on Body Composition among Sedentary Women of Manipur. International Journal of Human Movement and Sports Sciences, 9(4), 712 - 716. DOI: 10.13189/saj.2021.090415.

Copyright $\odot 2021$ by authors, all rights reserved. Authors agree that this article remains permanently open access under the terms of the Creative Commons Attribution License 4.0 International License

\begin{abstract}
Physical fitness was an important aspect for leading a complete life. Women, in general, have lesser involvement on a physical fitness regime. To maintain the youthfulness of body, regular physical activity and exercise was a key ingredient. This study aims to assess the effect of aerobic training on body composition among sedentary women of Manipur. The study made random inclusion of subjects who volunteer to participate in the training programme from Lairikyengbam Leikai, Imphal East District Manipur. Totally 30 subjects of age $46.5 \pm 4.9$ years who volunteer to participate in the training were selected and minimize as control group and experimental group with $\mathrm{N}=15$ each. Medical examination was conducted prior to training under registered practitioner. The training intensity was determining by using Karvonen formula. The training was given for 8 weeks regularly for 3 days alternately to determine the changes brought by training on body fat and fat free mass. The measurement was done before training as baseline score and after completion of 8 weeks as final score using Bio Electrical Impedance Analysis (BIA) method, TANITA TBF300. The paired $t$ test was used to analyze the data at a 0.05 level of significance for pre-and post-difference comparisons, followed by an independent $t$ test to compare the mean difference between groups using SPSS software20. It shows statistically significant decrease in body fat $(\mathrm{P}<0.05)$ while fat free mass shows statistically not significant $(\mathrm{P}>0.05)$. It also shows that fat mass has a significant difference between the experimental and control groups while fat free mass shows no significant difference
\end{abstract}

between groups. The result indicates that aerobic training can be an effective program for body fat reduction and positively alter one's body composition.

Keywords Body Composition, Fat Mass, Fat Free Mass, Karvonen Formula

\section{Introduction}

Sedentary behaviour diminishes the life expectancy of an individual, contributing more to the risk of cardiovascular diseases. World Health Organization (WHO) reported that $60-85 \%$ of the population from both developed and developing countries behave sedentarily[1]. Modernization was one such factor contributing to sedentary lifestyle, causing a possible form of a decrease in locomotion and body functioning. Such malfunction causes a major impact on our cardiovascular system, so most sedentary lifestyles were experiencing chronic heart diseases, obesity and high blood pressure [2].Regular exercise reduces the risk from various organic diseases and improves the different attributes of life[3]. Physical exercises involve whole muscle movement, this muscle activity raises the stimulation from different body parts. Our body thrives to adapt the various demands from muscular activity, resulting in modification and changes on our body physically and physiologically[4]. Aerobic training involves a certain sequence of exercises done 
continuously and constantly for at least 30 to 60 minutes, increasing heart rate to sustain load, the load may increase by $10 \%$ per week[5]. Exercising based on determining training intensity made training goal-oriented and efficient to extract most from physical activity. Exercise intensity may be low, moderate and vigorous measurable by the Metabolic Equivalent (MET) that are 1.6-3.0,3.0-6.0 and $6.0+$ METs, respectively and reflect difference in different individual adaptation to exercise[6]. According to the physical activity guidelines of America, 150 minutes of moderate-intensity aerobic activity or 75 minutes vigorous aerobic activity a week or a combination of moderate and vigorous-intensity throughout week[7]. Moderate intensity exercises made easier to sustain load longer under severe condition and have certain health benefits like lower blood pressure, weight management, improving cholesterol, mental stability, prevention osteoporosis etc.[8]. Body composition was one key factor determining an individual fitness level. It tracks changes on individual fat and non-fat components of our body. Accumulation of too much fat in the body poses a threat on heart and its related system, which is the major cause of obesity and chronic illness[9]. Moderate to high intensity exercises can improve aerobic capacity and beneficial in fat reduction, maintaining ideal body weight thereby increasing muscle mass[10]. Women after 30 cause massive changes on body and at higher risk from diseases such as diabetes, osteoporosis, anxiety, UTI, heart diseases, asthma etc. Study reveals that 31.00 percent of women aged 35- 54 have heart attacks[11]. Considering the need to raise concern among women who are less mobile and inactive, such study aims to bring out aerobic training among sedentary women of Manipur.

\section{Methods}

\subsection{Selection of Subjects}

For the study 30 Sedentary women of average age 46.5 \pm 4.9 years who volunteer to participate in the study were included randomly from Lairikyengbam Leikai, Imphal East District, Manipur. The subject was then divided into control group and experimental group. The subjects were determined about the purposes and protocols of the training and their signed consent was taken from them before the beginning of training. All the volunteers' subject underwent medical examination before the training under registered medical practitioner. The study was also recommended by the institutional ethical committee Manipur University no MU/IHEC/2020/023.

\subsection{Experimental Design}

It was experimental pre test and post test control group design. The experimental group participates in training while Control group was not given any training. Both groups measurement was taken twice as before and after the 8 weeks training to determine the effect of aerobic exercises on body composition (fat mass and fat free mass) among sedentary women of Manipur.

\subsection{Exercise Programme}

Moderate intensity aerobic training was assign to experimental group for 8 weeks series for about 45-60 minutes each day for 3 days in a week. Each training session begins with a 10 minutes warm up, 5 minutes cooling down and the rest for main activity. Selected aerobic exercises were given in circuit sequence up to 45 minutes with 3 minutes rest after each circuit at an intensity of 50-70. Background music was played to motivate the participants and build interest on training. The training intensity was determined following Karvonen formula[12]. To achieve the Target Heart rate of each subject, the exercise intensity was gradually increased after every 4 weeks. The sequence of aerobic exercises training was given in table 1.

\subsection{Experimental Procedure}

Measurement was made on early morning before breakfast, hydration and exhaustion adopting BIA method by using TANITA TBF 300 to measure the fat mass and fat free mass of the subject. The system needs manual input of body type, clothing weight, height in $\mathrm{cm}$, age in years, stand on electrode plate by naked dry feet in brief clothing. It feed output (fat mass and fat free mass) and recorded in $\mathrm{kgs}$.

\subsection{Statistical Analysis}

The data collected before and after the 8 week moderate-intensity regular aerobic session were given statistical treatment using IBM SPSS software.20. The data were analyzed by predicting mean and standard deviation and applying a paired sample t test followed by independent test in between groups to test the difference, significance at the 0.05 level. 
Table 1. Aerobic exercises training program

\begin{tabular}{|lc|}
\hline \multicolumn{1}{|c|}{ AEROBIC EXERCISES SEQUENCE } & NO.OF CIRCUIT \\
\hline MAMBO & \\
V STEP & \\
L STEP & \\
STEP TOUCH & $3(1-4$ WEEKS) \\
LEG CURL & $4(5-8$ WEEKS) \\
GRAPE VINE & \\
JUMP JACK & \\
STANDING OBLIQUE CRUNCHES RIGHT & \\
STANDING OBLIQUE CRUNCHES LEFT & \\
KNEE SIDE TO SIDE & \\
LUNGES & \\
SQUAT & \\
\hline
\end{tabular}

Table 2. Paired t test result of fat mass and fat free mass for experimental group

\begin{tabular}{|c|c|c|c|c|c|c|}
\hline \multirow{3}{*}{$\mathbf{N}$} & Variables & \multicolumn{2}{|c|}{ M SD } & MD & SE & P \\
\hline \multirow{3}{*}{15} & \multirow{2}{*}{ fat mass } & Pre test & Post test & \multirow{2}{*}{.68} & \multirow{2}{*}{$.002 *$} \\
\cline { 2 - 7 } & & $23.02 \pm 3.9$ & $20.47 \pm 2.5$ & & .5 & .29 \\
\cline { 2 - 8 } & fat Free mass & $40.7 \pm 3.6$ & $41.5 \pm 4.5$ & -.88 & .82 & .29 \\
\hline
\end{tabular}

Data presented as $\mathrm{M} \pm \mathrm{SD}=\mathrm{Mean} \pm$ Standard Deviation, $\mathrm{N}=$ no. of Subject, $\mathrm{MD}=$ Mean difference, $\mathrm{SE}=$ Standard Error. $\mathrm{P}=\mathrm{Probability,} \mathrm{t}=\mathrm{Students}{ }^{\mathrm{t}} \mathrm{t}$ distribution

*Significant at 0.05

Table 3. Paired t test result of fat mass and fat free mass for control group

\begin{tabular}{|c|c|c|c|c|c|c|}
\hline $\mathbf{N}$ & Variables & & & MD & SE & $\mathbf{P}$ \\
\hline \multirow{3}{*}{15} & \multirow{2}{*}{ fat mass } & Pre test & Post test & \multirow{2}{*}{-.10} & \multirow{2}{*}{.06} & \multirow{2}{*}{.12} \\
\hline & & $23.2 \pm 3.9$ & $23.3 \pm 3.8$ & & & \\
\hline & fat free mass & $39.07 \pm 5.1$ & $39.06 \pm 5.2$ & .006 & .08 & .93 \\
\hline
\end{tabular}

*Significance at 0.05

Data presented as $\mathrm{M} \pm \mathrm{SD}=$ Mean \pm Standard Deviation, $\mathrm{N}=$ no. of Subject, $\mathrm{MD}=$ Mean difference, $\mathrm{SE}=$ Standard Error. $\mathrm{P}=$ Probability, $\mathrm{t}=\mathrm{Students}{ }^{\mathrm{t}} \mathrm{t}$ distribution

Table 4. Independent $t$ test for mean comparison of experimental and control group

\begin{tabular}{|c|c|c|c|c|c|}
\hline $\mathbf{N}$ & Variables & & $\mathbf{M} \pm \mathbf{S D}$ & $\mathbf{t}$ & $\mathbf{P}$ \\
\hline \multirow{4}{*}{30} & E.G & \multirow{2}{*}{ fat mass } & $2.5 \pm 2.6$ & \multirow{2}{*}{3.8} & \multirow{2}{*}{$.001^{*}$} \\
\hline & C.G. & & $-.10 \pm .23$ & & \\
\hline & E.G. & \multirow{2}{*}{ fat free mass } & $-.88 \pm 3.1$ & \multirow{2}{*}{1.08} & \multirow{2}{*}{.28} \\
\hline & C.G. & & $.006 \pm .32$ & & \\
\hline
\end{tabular}

Data presented as $\mathrm{M} \pm \mathrm{SD}=$ Mean \pm Standard Deviation, $\mathrm{N}=$ no. of Subject, $\mathrm{MD}=$ Mean difference, $\mathrm{SE}=$ Standard Error. $\mathrm{P}=$ Probability, $\mathrm{t}=\mathrm{Students}{ }^{\mathrm{t}} \mathrm{t}$ distribution, $\mathrm{EG}=$ experimental group, $\mathrm{Cg}=$ Control Group.

*Significance at 0.05

\section{Results}

\subsection{All the Subject in both Experimental Group and Control Group was Compare Pretest and Post Test}

Table 2 shows the changes in fat mass and fat free mass of experimental group. The body fat mass was significant with mean \pm standard deviation $(\mathrm{M} \pm \mathrm{SD})$ for pretest and post test was $23.02 \pm 3$.9and $20.47 \pm 2.5$ respectively with $\mathrm{p}<0.05$ showing fat mass decreases significantly upon 8 weeks aerobic training. Minimal changes in fat free mass were observed as the $\mathrm{M} \pm \mathrm{SD}$ for pre test and post test was $40.70 \pm 3.6$ and $41.5 \pm 4.5$ respectively with $p>0.05$ showing no significant difference at 0.05 confidence level.

Table 3 shows the changes in fat mass and fat free mass of control group. The body fat mass and fat free mass was not significant with mean \pm standard deviation $(\mathrm{M} \pm \mathrm{SD})$ for pretest and post test was $23.2 \pm .3 .9$ and 23.3 \pm 3.8 ; $39.07 \pm 5.1$ and $39.06 \pm 5.2$ respectively with $\mathrm{p}>0.05$.

Table 4 shows the mean comparisons of pretest and post test of experimental and control group. It shows a significant difference in fat mass with $\mathrm{P}<0.05$ while fat 
free mass no significant difference with $\mathrm{P}>0.05$.

\section{Discussion}

Physical changes on body progress upon training. Correct training protocol was a basis for making training goal oriented. Our body burns out the excess fat in terms of calories during exercise, more intense the exercise more calories it burns[13]. This whole muscle activity stimulates the muscular tissues and this physiological adaptation to exercises causes hypertrophy of muscles[14] that manifest in decreasing fatty tissues. Aerobic exercises decreases percentage of body fat most significantly[15]. It shows $-3.7 \%$ decreases on body mass and $2.4 \%$ increase in muscle mass upon 12 weeks aerobic exercises intervention[16].The results from this study have confirmed that aerobic exercises training with music at $50-70 \%$ intensity of target heart rate given for 3 days a week's led to statistically significant decrease on body fat, these changes may be due to the intensity and frequency of exercises and sincerity of trainees. Study show that fat free mass may either remain the same or slightly increase[17].[18] Study by Kravitz et al.[19]shows that fat free mass increases upon 12 weeks aerobic program, however in the present study fat free was not significant, this may be due to the difference in the type and nature of training, moreover difference in geographical, dietary habit may also affect the outcome of training. Another study by Stosic et al.[20] reveals that dance aerobic can be an effective form of reducing body fat and increasing lean body mass.

This study shows the value of fat free mass in experimental a group higher from pre test though statistically not significant. Upon further extension of training, fat free mass may increase significantly. No significant changes were found on both variables (fat mass and fat free mass) of control group, $\mathrm{P}>0.05$.The statistic reveals a significant difference in fat mass in pre and post training between experimental group and Control Group with mean difference of $2.6 \mathrm{~kg}$. The main motive of training program was achieve relative to body fat mass however fat free mass reveal seldom changes if training was extended for more duration and at higher intensity, fat free mass may also show significant changes. This exercises programme may be follow as fat reduction aerobic training programmes. Statistic on fat free mass in experimental group shows the potency to increase muscular mass. So, further extension of training may build up the muscular tissue and reduce fat tissues.

\section{Conclusions}

This study shows the effect of aerobic training on body composition for the first time in women population of
Manipur. The study laid importance of physical exercises and training among sedentary women in Manipur. The study shows significant decreases in fat mass and minimal non-significant increase in fat free mass after training. Thus, this training model can be implemented for reduction of body fat as it show significant difference on fat mass after training comparing to control group.

\section{Funding}

The researcher thanks the University Grant Commission(UGC) for funding the study to pursue the study programme.

\section{Conflict of Interest}

None.

\section{Acknowledgement}

Researcher thanks all the participants for their effort and hands on making training successful. Researcher thanks all faculty of Department of physical education and sports sciences, Manipur University for their support and suggestion in the study.

\section{REFERENCES}

[1] World Health Organization. "Physical inactivity a leading cause of disease and disability, warns WHO", 2002, https://www.who.int/news/item/04-04-2002-physical-inact ivity-a-leading-cause-of-disease-and-disability-warns-who (accessed March,3,2020)

[2] Fentem PH, "Exercise in prevention of disease", British Medical Bulletin., vol 48, no. 3, pp.630-650, 1992. DOI:10.1093/oxfordjournals.bmb.a072568

[3] World Health Organization, "Physical activity.Who.int.", 2018, https://www.who.int/news-room/fact-sheets/detail/p hysical-activity (accessed April,4,2020)

[4] Ahlstrom D, "How exercise changes your body for the better", The Irish Times, https://www.irishtimes.com/news /science/how-exercise-changes-your-body-for-the-better-1. 2082767 (April,13,2020)

[5] Beer B, "The 10\% Rule: Does it hold True?" https://www.pogophysio.com.au. (accessed April.15,2020)

[6] Harvard School of Public Health "Staying Active" 2020, https://www.hsph.harvard.edu. (accessed April, 14, 2020)

[7] Health.gov. "Physical Activity Guidelines of America"https://health.gov/sites/default/files/2019-10/PA G_ExecutiveSummary.pdf (accessed April,16,2020)

[8] Mayo Clinic, "Moderate Intensity Exercises yields Big 
Benefits" Science Daily, 2008 https://www.sciencedaily.co m/releases/2008/01/080104123421.htm. (accessed April,19,2020)

[9] Body Volume, "The Importance of Body Composition", 2020, https://www.bodyvolume.com/post/the-importanceof-body-composition. (acceseed April.20,2020)

[10] Caporuscio J, "Weight loss plateau:Why they happen and what to do.", 2019.. Online available from https://www.medicalnewstoday.com/articles/326415 (accessed December 19, 2020)

[11] Crow S, "30 Health Issues Every Woman Over 30 Should Start Looking Out For. Best Life.”, 2020, https://bestlifeonline.com/womens-health-issues-over-30/ (accessed December 24,2020)

[12] Robert Wood, "Heart rate Karvonen Formula, Topend Sports website", 2010. https://www.topendsports.c om/fitness/karvonen-formula.htm (accessed December 26, 2020)

[13] Villines Z, "What Exercises Burn the Most Calories? 12 Exercises, Tips, and More", Medical News Today, 2020,https://www.healthline.com/health/what-exercise-bur ns-the-most-calories (accessed December 29,2020)

[14] BBC, "Long and short term effects of exercise - Ed excel Revision 2 - GCSE Physical Education" BBC Bitesize, 2019.https://www.bbc.co.uk/bitesize/guides/z367tyc/revisi on/2 (accessed January 2, 2021)

[15] Rizka Octaviana, Mohammad Furqon Hidayatullah, Agus
Kristiyanto, "Effect of low-impact aerobic dance and zumba exercises on body fat percentage in obese women", Malaysian Journal of Public Health Medicine. Vol. 20, no.1, pp.160-166, 2020. doi: 10.37268/mjphm/vol.20/no.1/art.49 9

[16] Pantelic S, Milanovic Z, Sporis G, Stojanovic-Tosic J., "Effects of a Twelve-Week Aerobic Dance Exercises on Body Compositions Parameters in Young Women", International Journal of Morphology, vol. 31, no.4, pp.1243-1250, 2013. doi: 10.4067/s0717-95022013000400 016

[17] .Wilmore JH. "Body Composition in Sport and Exercise: Directions for Future Research", MEd.Sci.SportsExerc, Vol.15, no.1, pp.21-31., 1983.

[18] Kostrzewa-Nowak D, Nowak R, Jastrzębski Z, et al, "Effect of 12-week-long aerobic training programme on body composition, aerobic capacity, complete blood count and blood lipid profile among young women", Biochemia Medica. 2015, Vol. 25, no.1, pp.103-113., 2015. doi:10.11613/bm.2015.013

[19] Kravitz, L., Heyward, V.H., Stolarczyk. L.M., \& Wilmerding, V, "Does step exercise with hands weights Enhance Training effects", Journal of Strength and Conditioning Research, Vol.11, no.3, pp.194-199, 1997.

[20] Stosic, Dejan \& Uzunovic, Slavoljub \& Velickovic, Sasa \& Zivkovic, Mladen \& Petrovic,Vladan \& Markovic, Jovan, "Effect of Dance Aerobic on Body Composition", International Scientific Conference FIS Communication pdf, 2016. 